\title{
Hauptversammlung 2017 in Berlin
}

\section{Tagungsort}

ELLINGTON Hotel Berlin, Saal „Femina“, Nürnberger Str. 50-55, 10789 Berlin

Tel.: 030-68315(0)/ Fax: 030-683155555

\section{Eröffnung der Hauptversammlung}

12.10.2017 Beginn/Ende: 09.30 bis ca. 18.00 Uhr

\section{Fortsetzung der Hauptversammlung}

13.10.2017 Beginn/Ende: 09:00 bis ca. 18:00 Uhr und 14.10.2017 Beginn/Ende: 09:00 bis ca. 13:00 Uhr

1. Eröffnung durch den Versammlungsleiter

2. Grußworte

3. Ehrungen

4. Festreferat

5. Diskussion zum Festreferat

6. Regularien

7. Fragestunde

(Die Fragen dürfen sich nicht auf Punkte der Tagesordnung beziehen und müssen mindestens eine Woche vor der Sitzung der Hauptversammlung in der Bundesgeschäftsstelle schriftlich eingegangen sein.)

8. Bericht des Bundesvorstandes

9. Diskussion des Berichts des Bundesvorstandes

a) Kernthema „Zukunftsweg Zahnheilkunde“: Impulsreferat

b) Kernthema „Qualitätssicherung“: Impulsreferat ZA Martin Hendges

c) Kernthema „Versorgungsforschung“:

Impulsreferat Prof. Dr. Christof Dörfer

d) Allgemeine Diskussion entsprechend Raster

10. Änderung der Geschäftsordnung der Hauptversammlung

11. Änderung der Satzung

12. Bericht der Kassenprüfer

13. Jahresrechnung 2016

14. Entlastung des Bundesvorstandes

15. Wahlen

15.1 Neuwahl des Bundesvorstandes

15.2 Neuwahl des Versammlungsleiters und seiner Stellvertreter 15.3 Neuwahl zweier Kassenprüfer und deren Stellvertreter

16. Genehmigung des Haushaltes 2018

17. Anträge

(Anträge, die die Tagesordnung verändern, müssen spätestens zwei Wochen vor der Sitzung schriftlich in der Bundesgeschäftsstelle eingegangen sein.)

18. Verschiedenes

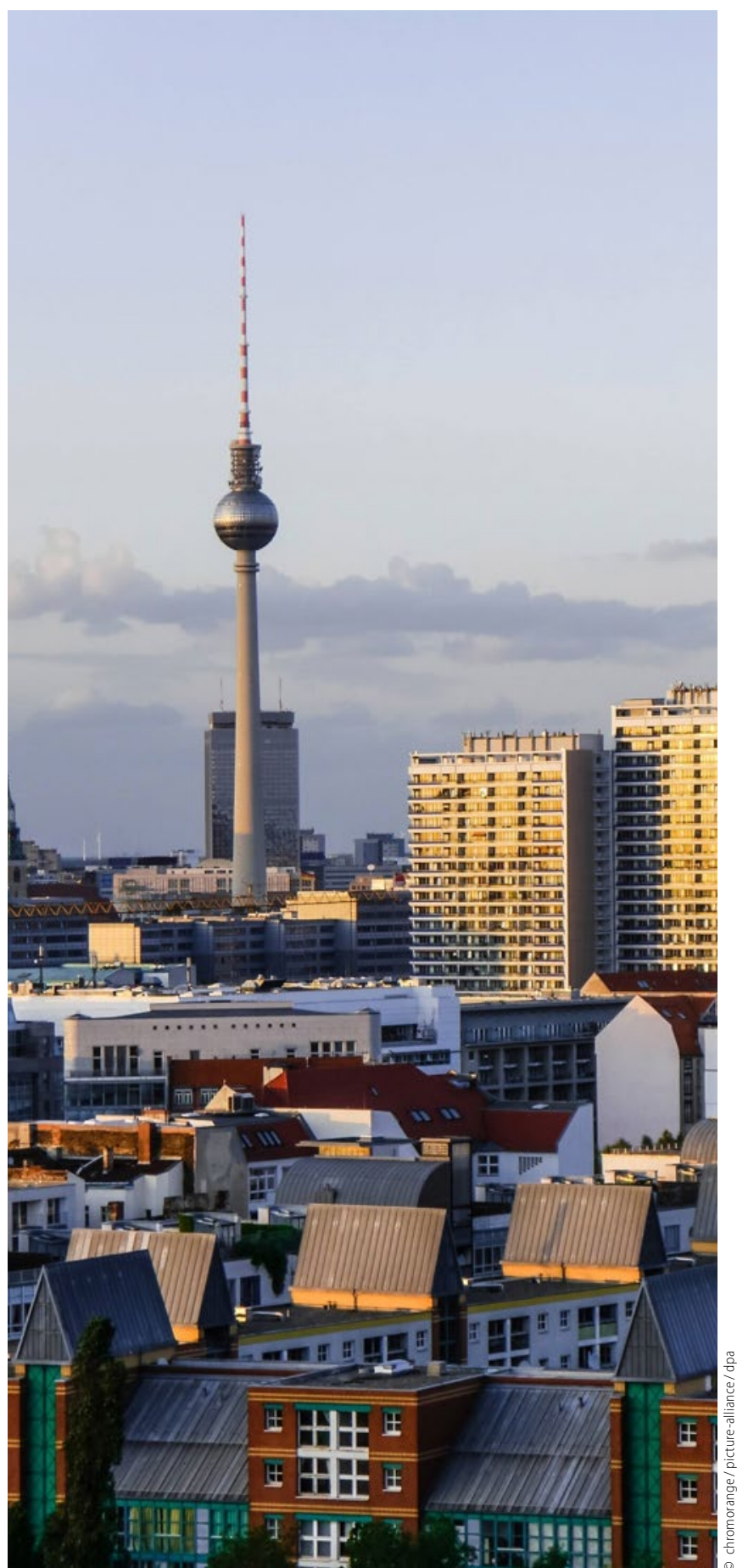

